Article

\title{
Expectations and Needs of Estonian Health Sector SMEs from Living Labs in an International Context
}

\author{
Katri-Liis Lepik *(D) and Merle Krigul \\ School of Governance, Law and Society, Tallinn University, Tallinn 10120, Estonia; mkrigul@gmail.com \\ * Correspondence: kllepik@tlu.ee; Tel.: +372-52-99267
}

check for updates

Citation: Lepik, K.-L.; Krigul, M.

Expectations and Needs of Estonian Health Sector SMEs from Living Labs in an International Context. Sustainability 2021, 13, 2887. https:// doi.org/10.3390/su13052887

Academic Editor: Mário José Baptista Franco

Received: 4 January 2021

Accepted: 26 February 2021

Published: 7 March 2021

Publisher's Note: MDPI stays neutral with regard to jurisdictional claims in published maps and institutional affiliations.

Copyright: (c) 2021 by the authors. Licensee MDPI, Basel, Switzerland. This article is an open access article distributed under the terms and conditions of the Creative Commons Attribution (CC BY) license (https:/ / creativecommons.org/licenses/by/ $4.0 /)$.

\begin{abstract}
Living labs bring experimentation out of otherwise closed R\&D departments to real-life environments with the participation of users and stakeholders. Living labs have been established in all the Baltic Sea countries. They operate in many sectors, but the way services are structured varies widely. This study is focusing on the limited options of small and medium-sized enterprises (SMEs) from Baltic Sea states to test and validate their products and services both in local as well as international contexts, and resulting limited access to foreign markets. This study comprises a qualitative content analysis of interviews with SMEs to identify the internationalization potential of living labs. In particular, the authors have analyzed the needs, expectations and obstacles of SMEs in the healthcare sector in Estonia. The authors found that testing and validation activities in living labs would be beneficial mostly for SMEs ready for entering international markets. Other services offered by living labs could be of interest to SMEs considering entering new international markets but have not achieved validation.
\end{abstract}

Keywords: living labs; open innovation; user involvement; health services; sustainability

\section{Introduction}

The world's population is ageing rapidly, especially in Japan and some European countries [1]. Ageing populations have considerable socioeconomic consequences, and therefore innovations in products, services and business models are needed in the health and well-being domain. Co-creation, user-centric and user-driven innovation methods are suggested as one way to find solutions to diverse health and well-being problems [2]. Methods such as co-creation and product testing in a real-life environment, helping companies to market their services and escalate to global markets, are at the core of the activities of living labs. These innovative methods are described as a collaboration between various Quadruple Helix actors [3].

There is no universally agreed definition of Living Labs (LL). They have been defined using various concepts such as a methodology, an organization, a system, an arena, an environment, and/or a systemic innovation approach [4]. Scholars and practitioners have provided many definitions of Living Labs, according to Claudio Dell'Era and Paolo Landoni [5]. Living Labs are described as user-centered, open innovation ecosystems involving user co-creation methods integrating research and innovation processes in reallife communities and settings [6,7]. Leminen [8] defined living labs as: "physical regions or virtual realities, or interaction spaces, in which stakeholders form public-private-people partnerships (4Ps) of companies, public agencies, universities, users, and other stakeholders, all collaborating for creation, prototyping, validating, and testing of new technologies, services, products, and systems in real-life contexts". A study by Leminen [9] analyzed about 70 different definitions and concluded that there are five main characteristics or perspectives which define a Living Lab: public-private-people partnerships (4Ps), real-life or life-like environments, research methodologies, conceptualizations and tools.

According to the European Network of Living Labs' definition, LLs "operate as intermediaries between citizens, research organizations, companies, cities and regions 
for joint value co-creation, rapid prototyping or validation to scale up innovation and businesses" [10]. LLs have common elements but multiple different implementations.

Living Labs can be referred to as organizations driven by practices enhancing open, collaborative innovation. They can also be described as spaces where open innovation and user innovation processes take place. In conclusion, they are places where experimentation to find new solutions is being developed. Promoters of the LL approach suggest that it can increase the likelihood that innovations will meet users' needs and thus lead to technologies or practices which are adopted more quickly and widely [11]. Based on the literature of the concept as well as the experiences of Living Lab practices of the authors, Living Labs are defined in this article as both an ecosystem and an approach (methodology, innovation approach).

Different paradigms and frameworks have been developed to assist private organizations to deal with innovation, such as open innovation [12], (lead) user innovation [13] and distributed innovation [14]. This has led to different innovation management approaches and organizational forms to cope with these new innovation models [15].

Key Living Lab characteristics that the authors have adopted include:

- a multi-method approach

- user engagement

- multi-stakeholder participation

- real-life settings

Co-creation and experimental testing of products in real-life cases are key aspects of living labs which facilitate companies' access to new markets. Based on the discussions in the "Product Validation in Health" project (ProVaHealth 2017-2020), three main types of support for small and medium-sized enterprises (SMEs) can be distinguished within Living Labs [16]:

- LLs offer support in order to rapidly commercialize and scale up their innovations and products to global markets.

- LLs offer SMEs efficient client validation opportunities and user feedback.

- LLs offer SMEs input for product development.

Co-creation and experimental testing of products in real-life cases are key aspects of living labs, which thereby help and support companies rapidly commercialize and scale up their innovations and products to reach global markets [4]. In summary, based on the discussion in the ProVaHealth project, the living labs' activities include the following stages: ideation, conceptualization, proof of concept, testing and developing of products/services with end users, adjustments and new testing, marketing and commercialization.

The number of officially certified LLs has been steadily growing since the launch of the European Network Living Labs (ENoLL) over a decade ago [17]. There are nearly 400 officially recognized LLs across the world. Currently there are 170 active LL members in ENoLL [18]. Importantly, the most popular LL thematic focus area among ENoLL members is health and well-being, which accounts for $44 \%$ of all LLs $(\mathrm{N}=74)$.

There are living labs in all the Baltic Sea countries in many fields of health and wellbeing. They also operate with different business models and provide a diverse range of services to their clients. According to the representatives of business associations and technology parks, there is a lack of sectoral as well as transnational co-operation in the Baltic Sea region, which slows down the development of innovative products and services. Quite often, various test lab infrastructures, including living labs, serve only locally or regionally. There is little matchmaking between the living labs and the SMEs in the region. Today, large healthcare companies are located in the Nordic countries and northern Germany. At the same time, the Baltic Sea region is one of the most dynamic healthcare markets in Europe, where the healthcare expenditure is growing fast and approaching the European average. Innovative healthcare SMEs are unevenly distributed among the Baltic Sea countries, especially in the Baltic States and Poland. They do not tend to have sufficient resources to 
carry out the necessary testing and validation activities and identifying the existing suitable living labs for them in the target countries could help them access destination markets [19].

The main aim of this article was to study SMEs in Estonia in the field of healthcare technologies and analyze the companies' needs and interests in testing and validating its products or services in living labs in the Baltic Sea region. The aim is to identify the demands, expectations and obstacles SMEs have for the living lab services in order to open an opportunity to enter the foreign market, but also in developing the product to be marketable including all steps before launching in the foreign markets.

\section{Materials and Methods}

This article focuses on SMEs based in Estonia and seeks solutions mainly for those SMEs operating in the market of healthcare products or services. There are a total of 25 companies in the SME category of Tehnopol's Connected Health Cluster [20]. An additional 5 companies that are not members of the Tehnopol's Connected Health Cluster can be found in the same category from the Startup Estonia website [21], and 4 additional healthcare SMEs registered in Estonia can be found on the AngelList website [22], totaling 34. The interview requests were sent to all identified 34 healthcare SMEs in Estonia, and 9 of them agreed to be interviewed and be part of this research. Hence, the sample covers approximately $1 / 4$ of the SMEs from the healthcare domain registered in Estonia, which can be found on the public websites of the SME associations. The interview requests were sent to all identified healthcare SMEs in Estonia, and 9 of them agreed to be interviewed for this research. In the framework of this research, the 9 SMEs are a representative sample as they represent various stages in product development and company development. Hence, their responses allow for making conclusions on needs, expectations and obstacles of SMEs of that sector. The companies in the final sample cannot be addressed homogenously, as they represent quite different aspects of health-related fields. Thus, the respondents of the interviews include companies focusing on top-level medical products with a high level of specialization, as well as companies providing support products or services for primary healthcare services (family doctors, medical clinics). Estonian SMEs are very small (ca. 93\% of the SMEs have up to 9 employees). The respondents were either in managerial positions or leading the development processes as they usually operate in multiple roles. The interviews were carried out during the project "Product Validation in Health" (2017-2020). The companies that participated in the study are at somewhat different stages of development. For instance, there is a company that has an idea to create a product and has developed the necessary algorithms, but in the absence of real testing opportunities cannot develop the product further. All interviewees had no previous practical experience in using LLs, the main reason being the simple fact that such an opportunity had never been offered before. "Previously haven't used a LL, because there hasn't been an option for this" [SME9].

Table 1 shows that the majority of companies in the sample are already in the market with at least one product or service, either at home or abroad, the first sale or pilot has been made and they desire to validate the entry into new markets. In the table, these companies are identified as "SME with validated products/services". However, two of the companies interviewed are early-stage SMEs, which means that they are not yet validated product/service providers. In terms of the business models, the companies are similar: the main goal is to sell to other businesses, and only three companies mentioned that the alternative is to sell directly to the consumer. In the last column of the table, the authors have classified the companies according to the classification compiled by the National Institute for Health Development (NIHD) in Estonia in order to provide a better overview of which medical institutions' products and services are targeted, thus giving an indication of the end customer [23]. The instructions of the NIHD have been followed while compiling the last column, which means that if the customer is a family health center, it is possible that the same product/service is also used by hospitals. Analyzing the field of activity 
from the point of view of both the company and the customer, it is considerably easier to understand which market segment the product is aimed at.

Table 1. Small and medium-sized enterprises that participated in the study. Compiled by the authors.

\begin{tabular}{|c|c|c|c|c|}
\hline & SME Status & Business Model & Field of Activity & Customers \\
\hline SME1 & $\begin{array}{c}\text { SME with } \\
\text { validated } \\
\text { product/service }\end{array}$ & $\mathrm{B} 2 \mathrm{~B}$ & $\begin{array}{l}\text { Personal } \\
\text { medicine }\end{array}$ & $\begin{array}{l}\text { Family } \\
\text { healthcare center }\end{array}$ \\
\hline SME2 & $\begin{array}{c}\text { SME with } \\
\text { validated } \\
\text { product/service }\end{array}$ & $\mathrm{B} 2 \mathrm{~B}$ & Medical services & $\begin{array}{l}\text { Family } \\
\text { healthcare center }\end{array}$ \\
\hline SME3 & $\begin{array}{c}\text { SME with } \\
\text { validated } \\
\text { product/service }\end{array}$ & B2B & $\begin{array}{l}\text { Medicine, } \\
\text { psychology }\end{array}$ & $\begin{array}{l}\text { Rehabilitation } \\
\text { institution }\end{array}$ \\
\hline SME4 & Early-stage SME & $\mathrm{B} 2 \mathrm{~B}$ & Healthtech & Hospital \\
\hline SME5 & $\begin{array}{c}\text { SME with } \\
\text { validated } \\
\text { product/service }\end{array}$ & $\mathrm{B} 2 \mathrm{~B}$ & $\begin{array}{l}\text { First-level } \\
\text { healthcare } \\
\text { software }\end{array}$ & $\begin{array}{c}\text { Family } \\
\text { healthcare center }\end{array}$ \\
\hline SME6 & $\begin{array}{c}\text { SME with } \\
\text { validated } \\
\text { product/service }\end{array}$ & $\mathrm{B} 2 \mathrm{~B}$ & $\begin{array}{c}\text { Software } \\
\text { development }\end{array}$ & Other \\
\hline SME7 & Early-stage SME & $\mathrm{B} 2 \mathrm{~B}$ & $\begin{array}{c}\text { Medical device } \\
\text { manufacturing } \\
\text { for use in } \\
\text { personal } \\
\text { Health care }\end{array}$ & Diagnostics \\
\hline SME8 & $\begin{array}{c}\text { SME with } \\
\text { validated } \\
\text { product/service }\end{array}$ & $\mathrm{B} 2 \mathrm{~B}$ & $\begin{array}{l}\text { First level health } \\
\text { care }\end{array}$ & $\begin{array}{c}\text { Family } \\
\text { healthcare center }\end{array}$ \\
\hline SME9 & $\begin{array}{c}\text { SME with } \\
\text { validated } \\
\text { product/service }\end{array}$ & B2B & $\begin{array}{l}\text { Software produc- } \\
\text { tion/occupational } \\
\text { health }\end{array}$ & $\begin{array}{l}\text { Specialized } \\
\text { medical unit }\end{array}$ \\
\hline
\end{tabular}

The majority of the SMEs provide primary healthcare products, the main customer of which is a family health center. This can be justified by the introduction of the system of family health centers in Estonia, which is one of the most multifaceted institutions in the healthcare market and thus the most attractive for entrepreneurs. Two companies offer their products for hospitals. One of them is an early-stage SME, but both of them are highly specialized. Three companies are involved in the provision of products and services for rehabilitation, occupational health or diagnostics, and one company is not directly classified as only a healthcare provider, as their services can be extended to other fields. They currently provide software solutions mainly to healthcare companies. The two companies wishing to offer products directly to the consumer as an alternative also consider pharmacies as their customers, which have an even larger market reach than family health centers. The sample shows that companies are mainly focused on developing products for primary-care facilities. This is significant as a versatile possibility of testing in living labs must be taken into account. For the research purposes, interviews with the CEOs were carried out. Qualitative content analysis is used. The results of the interviews are anonymized, and therefore the participating SMEs are indicated as SME1SME9, respectively, as well, the product and company names are replaced by general terms in the interview content (e.g., "company", "product"). In order to study SMEs in Estonia in the field of healthcare technologies, the interviews were focusing on the following: 
- the needs of SMEs for testing and validating products and services with health LLs in the Baltic Sea States;

- the expectations of SMEs to test and validate products and services with health LLs in the Baltic Sea States;

- the needs and expectations of the representatives of SMEs related to internationalization of LLs and their services.

\section{Results}

\subsection{The Needs of SMEs for Testing and Validating Products and Services}

Testing and validation plays an important role in bringing a product to the market, and carrying out these activities is an essential part of the product development process, especially in a highly regulated and competitive market for medical products. The needs and expectations of companies for testing and validation in LLs are analyzed below as SMEs have much more limited opportunities to test and validate their products in both local and international contexts and this is one of the barriers to accessing foreign markets. The need here means a process or activity already planned in the context of a company or a specific product, without which the company or its product would not be sufficiently successful to survive. In order to address the needs of SMEs in collaboration with health LLs in the Baltic Sea countries for testing and validation of products and services, those needs are first identified which are key impediments to development. The responses have been analyzed from the perspective of LLs, i.e., on the basis of the theoretical framework discussed above, and as the products of the SMEs are quite different, most problems have been identified in individual cases. The SMEs mainly described their needs from a product point of view, which is understandable, as most SMEs have one product that is expected to reach initial market volume in order to stay sustainable. Fewer have been able to engage in broader development, but in the idea phase, new solutions are being considered by several SMEs. Testing (including verification) is a check of the functional requirements by the customers for a product or service, in which case it is checked that all the specified conditions (including regulatory ones) have been met for the product. Four companies mentioned product testing as a problem and a critical issue for them, which is expected to be solved either independently or with the help of LLs. At the same time, SMEs use the opportunities available to them in local health facilities so that at least initial tests can be carried out.

"Regarding the goals and future, we want international growth and contacts with potential customers (e.g., hospitals, doctors), more testing and validations. We want to have functionality and business-readiness tested, could use more clinical testing and feedback. Up to now we have managed testing on our own, contacted hospitals and health care centers directly, thus some testing done in real-life conditions." [SME3]

"First, testing is needed and validation itself is not always mandatory but it is based on regional requirements." [SME4]

"We are testing in West-Tallinn Central Hospital on HIV+ patients, where most of re-occurring appointments are handled by the platform." [SME8]

The feedback mentioned by SME3 and working on a solution with a larger number of users is something that is available through special testing services. Again, buying such a service means there is a testing service that creates the right conditions for product testing and that there is sufficient funding to test. While product testing and verification take place on a product which is still in the final stages of development, product validation takes place in a traditional company for a market-ready product. Validation is the verification in real life (including in the lab) with end users to verify if the product or service corresponds to the needs of the end users and is acceptable for them. To some extent, this aspect reduces the opportunity for SMEs that are primarily looking for validation in living labs to participate in the co-creation with users offered by the living lab, as the failure to validate a product is a sign of a need to return to the development phase. Validation was mentioned 
as a need by 6 SMEs, but from two significantly different aspects: clinical validation from the perspective of the Conformitè Europëenne CE marking or usability, and market validation from the perspective of entering new markets. It is understood that validation is so important, especially in the context of the healthcare sector, where EU regulation determines exactly how many cases must be validated and what conditions must be met in order to obtain the CE marking [24].

"Is there an option for clinical evaluation/validation? ... The main obstacle now is the lack of CE-certificate. Our company has some experience in using open facilities for testing, but currently we need so-to-say final validation/medical evaluation, trial." [SME7]

If a producer wants to market its product as a medical device, clinical validation is as important in the life cycle of a new medical product as testing and adequate validation. Thus, the SME company may already have the product ready for the market, but the sale cannot take place because there is not necessary product labeling, i.e., validation carried out to obtain it.

"Hardware and software are market-ready but will require medical evaluation before sales are possible. There are existing contracts already with customers (pharmacies) willing to sell the product after evaluation. The current goal is to get the main product certified as a medical device and bring it to the market." [SME7]

"In [product's] case, validation is mandatory for CE-certificate." [SME4]

The validation of the usability mentioned in the second aspect presupposes that the producer is able to make changes to a product already on the market, for which it is necessary to gather a sufficient volume of user input to be sure of the success of the product on the market. In part, this expectation coincides with feedback from users in the framework of living labs.

"The product is validated in few locations in real conditions, but mostly for its attractiveness for end-users, user experience and content-what lacks is more functional feedback and validation from more customers (doctors), to make the app more suitable for wider clinical use." [SME3]

The previous example shows that the SME already considers the market to be validated and wants to improve some part of the end-user-validated product, because it does not consider the functionality created for the other segment of end users to be sufficient. Product validation can also be understood simply as the existence of paying customers, which may mean more for the SME1 (financially) than pre-market research.

"Currently we are continuing validation of a new product on a closed test-group, who are actual paying customers..." [SME1]

In some ways, it illustrates the problem of SMEs in mobilizing the necessary resources, as validation on the part of customers is generally not a recommended practice. However, validation of (foreign) markets cannot be considered less important than clinical validation, as differences between countries in the medical sector are large enough so it makes sense to pursue one market but ignore the other.

"We are mostly focused on the UK, but not Ireland as the medical sector is too conservative there." [SME4]

A SME as a provider of an innovative service or product may therefore have difficulty accessing a new market because the product is too novel for the market. However, there are companies for whom market validation, the pursuit of new markets, is a basic need at this stage of development. For example, SME2 considers market validation and product acceptance as a problem that living labs are trying to find a solution to. On the one hand, problem solving allows the use of LLs to accelerate market entry; on the other hand, the feedback from real-time product validation allows the SME to provide better input for service development and at the same time signals market readiness to accept the product. 
"It's not the technology which needs to be tested, but rather the product which is enhancing communication between different parties—so the market readiness/validation for new markets is under question." [SME2]

SME8 has carried out the desired market research and validated the markets in the past, which may mean that the company is confident enough in its idea that it will be able to carry out extensive research worldwide before the product becomes marketable. However, getting it done at a very early stage gives later confidence in product development, as well as the ability to take into account the local specificities of different countries.

"We have performed the market research in 10 countries (Finland, Sweden, Norway, Latvia, Lithuania, Denmark, Ghana, Kenya, Uganda, Japan), so that the product would be easily adaptable in any country." [SME8]

The expectations of SMEs to test and validate products and services can be interpreted in two ways in the context of this article: the company's long-term needs, and expectations to certain living lab(s).

"We are interested in everything available. ... genetic algorithm development, pharmacogenomics, nutri-genomics... but also simple market tests, app testing, validation, translation of an application."[SME1]

"We could use a bit of everything: real market conditions, market readiness evaluation by a patient and a doctor..." [SME2]

The responses to the interviews have again been analyzed in the context of the LLs framework and this section focuses on testing and validation. As a general expectation from the perspective of a specific product or SME, for example, the hope was formulated that next year it would be possible to reach any clinic around the world with their product. In some cases, LLs in the Baltic Sea region are asked to help develop, test and validate specific functionality or provide user feedback on a product prototype, which is what a LL could by definition offer on a sufficiently broad and real-life basis.

"We mostly wish to develop and test/validate in LL-s: a patient self-reporting about functionality. Right now the communication is one-sided from a doctor to a patient." [SME8]

"LLs are very useful for carrying out research projects in the actual location where the resulting products will be later used. For example find doctors who would actually want to use the software and validate/provide feedback regarding the use of algorithm and functionality." [SME5]

"More research feedback needed on psychological support for end-users." [SME3]

In the example above, SME3 has requested research results from medical institutions on the effectiveness of a product in providing treatment. A separate problem is the situation where the company does not have the necessary resources (database with raw data) to support testing its product.

"The use of LLs would be beneficial for the company only when the patient data which describes the development of diseases and results of cure provided are present in the LL. A LL would have full datasets for illnesses, symptoms and results of cure, or a LL has access to aforementioned datasets ... Should there be any control-or test-databases, the company can run the tests on those." [SME4]

In some cases, it is difficult to come up with a solution, because it seems that the product being developed is too far advanced. Expectations related to validation in LLs were not raised as an independent topic by any SME representative. However, validation related to other activities was mentioned on a few occasions. SME2 hopes that LLs will provide an opportunity (service) not only for testing and validation but also for market validation, which, using the example discussed above, is the main need for a given company and its core service. Here, the respondent has specified that they would be interested in testing the insurance and financial model in the LLs. 
"New ideas for the current product can be most helpful. For example new ideas for the treatment plan, screening of risk patients.... We are interested in where the service is suitable, such as medical centers, health care centers. Ideally also interested in testing the insurance and financial side, the application of which universities could measure." [SME2]

SME1 has an expectation for a more diverse user base than participation in previous projects and the use of testing services has allowed.

"I attempted to cooperate in Ireland and France with local service providers to test the application, but the project didn't receive grants." [SME1]

The needs and expectations of the representatives towards the living labs will be discussed in the next section.

\subsection{The Needs and Expectations of the Representatives of SMEs Related to Internationalization of} LLs and Their Services.

As a specific idea that LLs could address and offer as a popular service, one of the companies proposed integrating well-being data, i.e., data from all smartwatches and other health products, into disease data to analyze both data accuracy and lifestyle and allow doctors to share recommendations based on the outcomes.

"For example, an idea for LL-s: how to integrate well-being data with data for diseases into one dataset/entity, to be able to analyze the whole picture. E.g. data from various gadgets, smartwatches, etc., in one dataset with medical data. Also, how do these different types of data interact and match." [SME4]

In order to find out what services could be provided by health LLs in the Baltic Sea States to facilitate the access of SMEs to foreign markets, other aspects mentioned in the interviews from the perspective of internationalization were analyzed. A justification for this can be found, for example, in the answer of one respondent:

"Different regional settings like a local language require a lot of work to implement-for now, there is no point in developing products for smaller markets. It is worthwhile to develop the product for Estonia only as long as there are avid consumers and the development is paid for, otherwise the market here is too small." [SME4]

Other respondents who have some international experience agree to it: from companies with customers around the world in many different countries to companies that have made some effort to establish themselves in European countries.

"We plan firstly to ensure ourselves on the local market, then go country-by-country. Since it's a medical appliance, we can't go global with the first app, we need to focus on a country and grow that way" [SME1]

Although the task of LLs is not directly to assist companies in internationalization, a network of LLs operating in different countries helps, if not to reach the market, then at least to gain experience and an initial market overview.

The needs of the SMEs mentioned have been summarized in the Figure 1 below. 


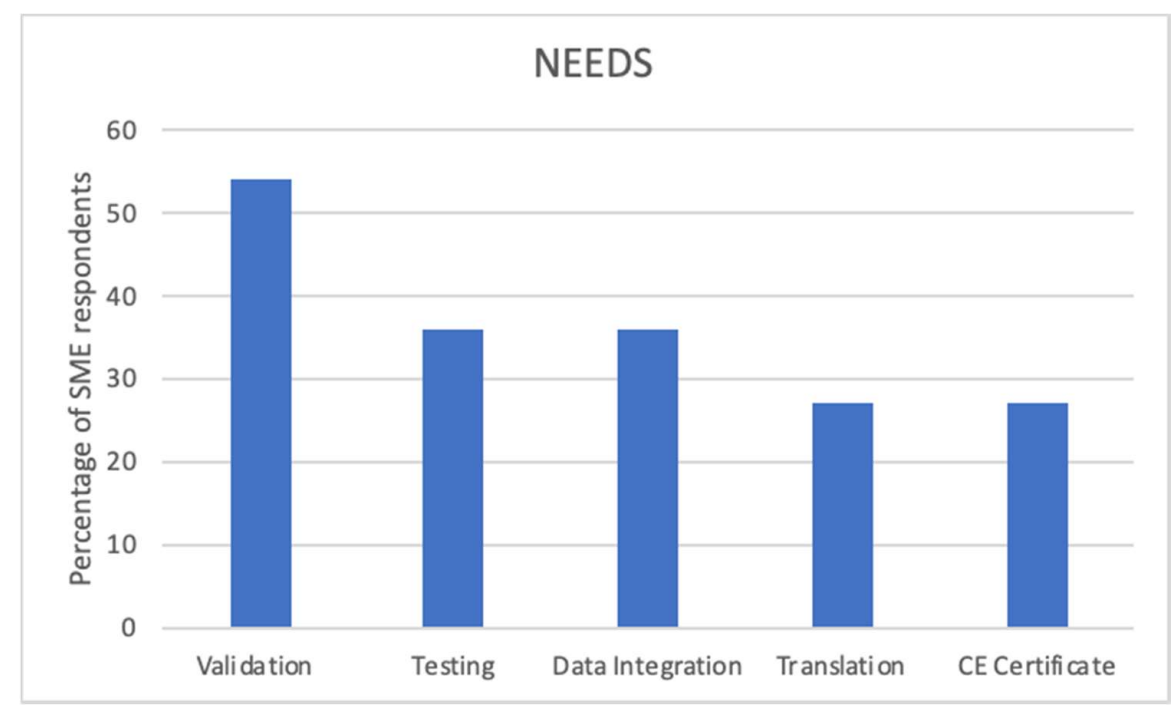

Figure 1. The needs of the SMEs. Compiled by the authors.

\subsection{The Obstacles of the Representatives of SMEs Related to Internationalization}

Although internationalization was mentioned as a goal by all participating companies, there are various additional issues, which proved to be obstacles. The main concerns include translation, the specificities of the markets, finding suitable partners, but also the lack of clinical validation, which hinders sales and the lack of a foothold in the domestic market.

"For a new market, the most important would be translation of current products but when dealing with genomics, we need to deal with local market specifications." [SME1]

"Growth could be quicker, we need partners, hopefully via different projects. It means hard work to enter a new country or a market." [SME2]

"Future internationalization is imminent and will happen after the product is on the market in its own country." [SME8]

It is possible to solve most of the above problems with the help of a network of LLs, with the exception of translation, which, due to the specificity of medical devices, may still be a task for which the SME must find its own resources.

"What would it mean to move medical information/data between the Baltic Sea countries?

Or is it still so that a local company can use only local medical systems?" [SME9]

The legislation regarding General Data Protection Regulation (GDPR) was mentioned as a problem as the producers have to take it into account, either for existing products or for projects still in the concept phase.

"There are several other projects in line, related to personal healthcare and telemedicine. For example child diabetes data is in the cloud, the main problem is data protection." [SME7]

"Digital appointment software platform to provide secure communication and information sharing between a patient and doctors which would follow the required laws and regulation is an issue." [SME8]

As far as innovation is concerned, the products of all the companies participating in the study are innovative, but for the most part they involve closed innovation, in some cases an implementation of an innovative idea coming from a closed user group.

"Previous LL experience was much waited for, but it didn't happen. Our company has created its own kind-of closed LL since it deals with innovative product which needs testing in a closed circle." [SME1] 
Several SMEs mentioned various resource-related issues. In their responses from direct financial resources to production and human resources. Various forms of cooperation are used to gather feedback from users, as well as consultations with experts. Consultation with experts in product development from both a medical and technological point of view, as well as the need to create the necessary documentation, was described by several companies. Lack of financial resources and time were highlighted as well as the hope that living labs would be able to provide a sufficient number of test cases to perform the tests required by the regulation of medical devices. From the point of view of funding, many were interested in the question of financing participation in LLs, but the question of amount of time needed was raised as well.

"The participation in the current project is highly expected, but we also need to consider the timeline and effort taken." [SME2]

The existence of the necessary human resources was raised as a concern.

"We are very interested in clinical evaluation possibilities as the requirement for getting the product certified means using minimum 105 patients/users from different age groups and also getting medical personnel's approval. We could use advice in documenting, certification, etc., as the main product is evaluated as class $2 A$ - product (which monitors life-critical parameters), meaning that all documentation needs to pass audits." [SME7]

As the SME might not have the resources to comply with the entire regulation, it is possible to test the product in LLs as a suitable solution, allowing access to test cases under the conditions required. In the latter example, the SME also mentioned the documentation as a problem area that needs to be addressed when preparing the product for market readiness. As the documentation required by the European Union is extensive, other respondents faced the same problem. From a regulatory point of view, concerns about the speed of the flow were also raised.

"The issue is that healthcare is a slowly moving market, especially its documentation flow." [SME8]

On the regulatory side, there may be (unintentional) market restrictions if a SME can only market a product to specific healthcare facilities because there is no financial support from the insurer to customers when selling to other institutions, which makes the product unattractive.

The obstacles for the SMEs mentioned have been summarized in the Figure 2 below.

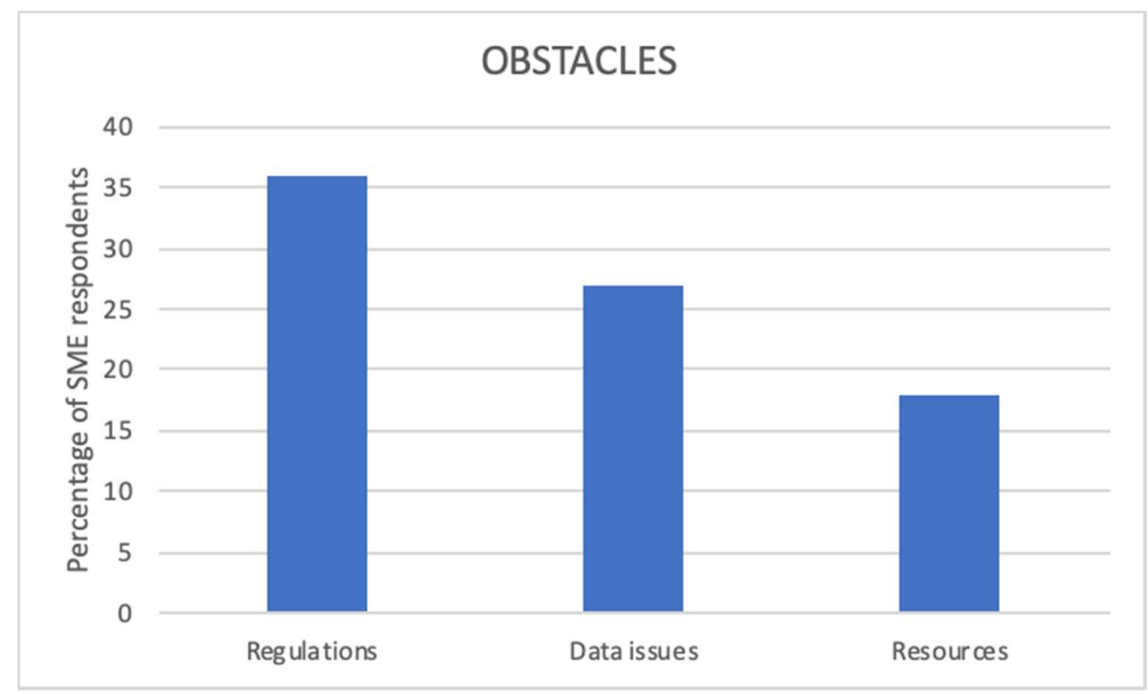

Figure 2. The obstacles of the SMEs. Compiled by the authors. 


\section{Discussion}

It became evident that testing is an important step in product development for the SMEs, and hence their participation in LLs can be helpful. The need for validation often stems from regulations, which set specific criteria for the number of cases required for product validation and the documented activities to be carried out, noting the specific nature of the healthcare market. Looking at market validation in isolation, which means that the market is assessed as suitable for entry or not, the producer can define and then focus only on the preparation of a specific product suitable for the specific market(s). However, the validation of a new market, going beyond the home market, is a step where a SME may need the help of international organizations that have the necessary capacity to do so.

Leaving aside entrepreneurs who want almost everything (if given for free), it is not surprising that testing and validation are perhaps not the biggest expectations of SMEs from LLs. Based on the interviews, it can be concluded that the expectations of the SMEs extend the limits of the possibilities of the LLs in certain stages. It can be argued that both testing and validation are already real-enough needs for entrepreneurs, and they have been tried in the product development cycle already. Therefore, the expectations of LLs include wishes to discover something extraordinary, unprecedented.

Internationalization is an essential need for all interviewed SMEs. This is due to the small size of the domestic market as well as the SME's strategy. Certain participating SMEs are already operating successfully on the international market, others are still taking the first steps, but the message of the respondents is the same: one cannot operate in only one market. LLs are seen as a way to find partners in foreign markets, as well as for both market and clinical validation. It is difficult to guess whether, for example, a sticker with the text "Tested in Living Lab" adds value to the company's products or not. The problems posed by legislation at both the local and EU levels can be highlighted. There remains a question if living labs could be the organizations that lobby for the changes in regulations on behalf of the SMEs. Although there is an international standard for medical data, different countries have varied healthcare systems and therefore often exchange of data happens using more traditional methods than the technological level could allow. In terms of legislation, the GDPR is a matter of concern as a new regulation that companies processing personal data must take into account. The case where a SME can only offer a product to specific institutions was mentioned as a regulatory restriction, because otherwise it would be categorized as not insured by health insurance and thus become less attractive to customers. The interviews gave the impression that the participating companies have so far approached innovation mainly in the framework of closed innovation and therefore do not demand co-creation that living labs could offer. Based on the answers, a couple of products and companies can be identified, which seem to need this service at the current stage of development.

Although, co-creation is one of the characteristics of LLs, but no respondent explicitly mentioned it as an expected activity. At the same time, everyone expects feedback from users, and it is expected that the necessary channels have been created, for example, by launching a separate feedback module for the app that comes with the product. It can be assumed that since most of the interviewees are already in the market or in the validation phase, they may be looking for co-creation opportunities in the LLs for new ideas that are not yet ready for testing.

Any feedback from users is highly appreciated by SMEs, cooperation with customers is taking place, and in many cases, broader feedback is one of the reasons for participating in LLs. The use of the same techniques in LLs to accelerate innovative product development, such as the hackathon format, is expected by SMEs. The number of times an aspect was mentioned shows the relevance of it for the SMEs. The needs were most talked about in terms of internationalization (23 cases), validation (18 cases) and product development (11 cases), but as mentioned above, the first product or service on the market (mentioned in 108 cases) and its development is so important for the SME that many respondents focused 
on how to get involved in LLs having their product needs in mind. Although one of the characteristics of LLs is the acceleration of development, perhaps entrepreneurs who want to validate a product prototype are still too optimistic, because in this case the readiness to make changes to a product already in the final development stage should be taken into account. In principle, this is possible taking an agile development approach, but is a quite labor-intensive task. However, in such a case, is product development not already at a stage where co-creation with users in LLs is proving difficult, because the product development and marketing strategy is already in place for the company? This study does not have the necessary data to determine it. However, they are still willing to participate in LLs to solve other needs that hinder the development of the company or the product. Distinguishing between validation and testing can be difficult for medical devices, as there may be no alternative to validation activities other than a laboratory or other closed environments, due to the high degree of specialization of the product and the need for controlled conditions. The need for testing was mentioned by the companies in cases when this activity is the main obstacle at the current stage of product development. Translating the product into foreign languages was seen as a barrier, which may be due to either regulations or simply a realistic chance of capturing the market. Providing translation is not a service LLs should provide but they could rather assist with cultural awareness and business environment.

\section{Conclusions}

SMEs and living labs share many common characteristics, thus it is logical that SMEs could speedily enter a market, when using the framework provided by living labs. The current article provided analysis primarily from the perspective of testing and validation activities in living labs that should enable faster internationalization of SMEs. The study used qualitative content analysis of transcribed interviews. Participants from 9 SMEs took part in the interviews. In particular, the authors have analyzed the needs, obstacles and expectations of SMEs in the healthcare sector in Estonia. Testing and validation were considered as primary obstacles for companies in reaching a foreign market. If the product is not (clinically) evaluated as regulations demand, then access to European markets is not possible, and as a new company, it may be difficult to find the required resources. Living labs could be used to carry out market validation, whether the manufacturer's/producer's strategy is suitable, or the product/service requires major changes before attempting to enter a foreign market. Although testing and validation were considered main problems in the study, SMEs' representatives also named other issues which they hoped to solve via living labs, mostly in the context of accessing a foreign market, e.g., wider specialistaudience able to give needed feedback to products; consultants of both medical as well as technical areas; options for co-development and help with documentation. Issues related to product translation into different languages were brought out, as one of the requirements for accessing the market and users, but in this case, living labs might not be the place to find a solution. Legislation and regulation were mentioned, often in the same sentence with GDPR but also in relation to market control mechanisms created by an insurer. It may be possible to find advice for these issues from living labs, but primarily, these should be addressed to public bodies.

In conclusion, the SMEs would benefit from Living Labs if they could enable options for the SMEs to carry out different activities to develop, test, validate, etc., their products or services and finally help to market them. Thus, the process from the idea to the finalized product is expected to become quicker and cheaper, enabling the SME to allocate more resources for developing new products and improving existing ones. Living Labs also help out with expert advice or help find new partners, in case this is the main need for the SME. In turn, the Living Labs could become more sustainable with their offering if they corresponded better to the needs and expectations of the SMEs.

The authors presume that the main findings of this research could be generalized to the Baltic Sea countries. Further research should include the comparative analysis of the needs and obstacles of SMEs while using the Living Labs services in those countries. 
Author Contributions: Conceptualization, resources, methodology, analysis of data, writingoriginal draft preparation; K.-L.L.; discussion and conclusion K.-L.L. and M.K.; review and editing, K.-L.L. All authors have read and agreed to the published version of the manuscript.

Funding: This research was funded by the Interreg Baltic Sea Region Programme 2014-2020 in the framework of the project "\#R039 Product Validation in Health".

Institutional Review Board Statement: Not applicable.

Informed Consent Statement: Informed consent was obtained from all subjects involved in the study.

Data Availability Statement: The data presented in this study are available on request from the corresponding author.

Conflicts of Interest: The authors declare no conflict of interest.

\section{References}

1. OECD. OECD Factbook 2015-2016: Economic, Environmental and Social Statistics; OECD Publishing: Paris, France, 2016. [CrossRef]

2. Ramaswamy, V.; Ozcan, K. What is co-creation? An interactional creation framework and its implications for value creation. J. Bus. Res. 2018, 84, 196-205. [CrossRef]

3. Robert, A.; Anu, J.; Pasi, K.; Tatu, P. Exploring Quadruple Helix Outlining User-Oriented Innovation Models; Final Report on Quadruple Helix Research for the CLIQ Project; Tampereen Yliopistopaino oy Juvenes Print: Tampere, Finland, 2010.

4. Ståhlbröst, A. A set of key principles to assess the impact of Living Labs. Int. J. Prod. Dev. 2012, 17, 60. [CrossRef]

5. Dell'Era, C.; Landoni, P. Living Lab: A Methodology between User-Centred Design and Participatory Design. Creativity Innov. Manag. 2014, 23, 137-154. [CrossRef]

6. Ballon, P.; Schuurman, D. Living labs: Concepts, tools and cases. info 2015, 17, 4. [CrossRef]

7. Leminen, S.; Westerlund, M.; Nyström, A.-G. Living Labs as Open-Innovation Networks. Technol. Innov. Manag. Rev. 2012, 2, 6-11. [CrossRef]

8. Leminen, S. Coordination and Participation in Living Lab Networks. Technol. Innov. Manag. Rev. 2013, 3, 5-14. [CrossRef]

9. Leminen, S. Living Labs as Open Innovation Networks-Networks, Roles and Innovation Outcomes. Ph.D. Thesis, Aalto University, Espoo, Finland, 2015.

10. European Network of Living Labs. Homepage. Available online: https:/ / enoll.org (accessed on 8 January 2018).

11. Bronson, K.; Devkota, R.; Nguyen, V. Moving toward Generalizability? A Scoping Review on Measuring the Impact of Living Labs. Sustainability 2021, 13, 502. [CrossRef]

12. Chesbrough, H. The Logic of Open Innovation: Managing Intellectual Property. Calif. Manag. Rev. 2003, 45, 33-58. [CrossRef]

13. Von Hippel, E. Democratizing innovation: The evolving phenomenon of user innovation. J. Betriebswirtsch. 2005, 55, 63-78. [CrossRef]

14. Sawhney, M.; Prandelli, E. Communities of Creation: Managing Distributed Innovation in Turbulent Markets. Calif. Manag. Rev. 2000, 42, 24-54. [CrossRef]

15. Schuurman, D.; Tõnurist, P. Innovation in the Public Sector: Exploring the Characteristics and Potential of Living Labs and Innovation Labs. Technol. Innov. Manag. Rev. 2017, 7, 7-14. [CrossRef]

16. Tallinn University. Product Validation in Health-Living Lab Concept: Review of good practices of health Living Labs; Tallinn University: Tallinn, Estonia, 2019. Available online: https://scanbalt.org/wp-content/uploads/2020/03/Raport1.pdf (accessed on 10 December 2019).

17. Garcia Robles, A.; Hirvikoski, T.; Schuurman, D.; Stokes, L. Introducing ENoll and Its Living Lab Community; European Network of Living Labs: Brussels, Belgium, 2016.

18. Research Day—Conference Proceedings 2017. Open Living Labs Day 2017. ENoLL_European Network of Living Labs. Available online: https:/ / biblio.ugent.be/publication/8534167/ file/8534169.pdf (accessed on 5 October 2018).

19. ScanBalt. About ProVaHealth. Available online: https://scanbalt.org/livinglabs/provahealth/ (accessed on 4 January 2018).

20. Connected Health Cluster. Homepage. Available online: https:/ / connectedhealth.ee (accessed on 4 January 2018).

21. Startup Estonia. Available online: https:/ / startupestonia.ee (accessed on 4 January 2018).

22. AngelList Venture. Invest Deal-by-Deal in World-Changing Startups. Available online: https://angellist.com (accessed on 4 January 2018).

23. The National Institute for Health Development. Classification of Health Care Service Provider. Available online: http:/ /www.tai. ee/images/Classification_healthcare_service_providers.pdf (accessed on 21 January 2018).

24. European Commission. Internal Market, Industry, Entrepreneurship and SMEs. Sectors. Medical Devices. Regulatory Framework. Available online: https:/ / ec.europa.eu/growth/sectors/medical-devices/regulatory-framework_en (accessed on 4 January 2019). 